\title{
Por Que Revisitar o Debate entre BERGSON E EINSTEIN? ${ }^{\text {I }}$
}

\author{
Márcio Barreto
}

\begin{abstract}
RESUMO: Bergson e Einstein participaram de uma conferência no Collège de France, em Paris, no mês de abril de 1922. Muitos desencontros entre o físico e o filósofo, no que diz respeito à questão do tempo, são já superados, se considerarmos a existência de processos dinâmicos instáveis, mas ainda permanece atual a questáo da interioridade do tempo à ciência e, portanto, a possibilidade de retomada da complementaridade entre a ciência e a metafísica, proposta por Bergson, como necessária para a compreensão da complexidade dos problemas contemporâneos. A partir das concepçóes de intuição em Bergson e Einstein, este artigo explora as dificuldades e as potências do diálogo entre a Física e a Filosofia.
\end{abstract}

PALAVRAS-CHAVE: Bergson. Einstein. Tempo.

Contrariamente à ideia de que os objetos tecnológicos são sempre subprodutos da ciência pura, muitas teorias surgiram na física, com base em soluçôes técnicas de alguns problemas. À medida que o carvão mineral ganhava importância nas transformaçôes socioeconômicas do século XVIII, um problema técnico ia se agravando: a formação de água no interior das minas. As inundaçôes ocorriam com a escavação, e a profundidade dificultava a remoção da água até que as máquinas térmicas de Newcomen resolveram esse problema e lançaram as bases da Revolução Industrial. A conversão de calor em movimento operada por tais máquinas foi inspiradora para a formulação de leis da natureza, as quais emergiram no século XIX, como a hipótese de conservação da energia anunciada por Mayer, Joule, Colding e Helmholtz, e o conceito de entropia proposto por Clausius.

Como observou Peter Galison (2005, p. 39), “[...] diferentemente da imagem tradicional, segundo a qual Einstein foi um cientista-filósofo, ele

\footnotetext{
${ }^{1}$ http://dx.doi.org/10.1590/S0101-31732016000100005

2 Professor da Universidade Estadual de Campinas (UNICAMP), na Faculdade de Ciências Aplicadas (FCA/UNICAMP) e no Laboratório de Estudos Avançados em Jornalismo (Labjor/IEL/ UNICAMP); membro do grupo de pesquisa Conhecimento Tecnologia e Mercado (CTeMe/IFCH/ UNICAMP) e do Centro de Ciências Humanas e Sociais Aplicadas (CHS/FCA/UNICAMP). E-mail: marcio.barreto@fca.unicamp.br
} 
redefiniu a simultaneidade a partir de necessidades práticas existentes em seu tempo". Einstein encontrou no escritório de patentes de Berna - onde começou a trabalhar em 1902 - uma tribuna de honra para assistir ao desfile das novas tecnologias que ligavam o triunfo da eletricidade sobre a mecânica aos sonhos da modernidade. O problema a ser resolvido na época era o da sincronização de relógios necessária ao deslocamento de tropas e ao bom funcionamento da malha ferroviária e das linhas de telégrafo. Foi procurando uma teoria capaz de explicar de forma única os fenômenos do magnetismo e os princípios da mecânica que Einstein construiu uma teoria revolucionária, todavia, é bastante provável que a revisão do conceito de simultaneidade, ponto de partida da argumentação da teoria da Relatividade, tenha sido inspirada no problema da sincronização de trens e de relógios. Outro problema aparentemente técnico a ser solucionado era o resultado negativo dos experimentos de Michelson e Morley para determinar a velocidade da Terra em relação ao éter.

As soluçôes de Einstein foram consolidações teóricas e tecnológicas de tendências que já vinham sendo esboçadas há muito tempo e que deslocaram a percepção do senso comum para um plano inacessível à experiência imediata dos sentidos, mas que mantêm lastro no real através da abstração matemática de um espaço-tempo quadridimensional e de comprovaçóes experimentais.

As teorias de Einstein não seriam possíveis sem o aparato tecnológico disponível na virada do século XIX para o século XX.

Em 1899, quando Rutherford e Giesel tornaram possível a utilização dos raios beta e quando a radioatividade foi descoberta, Walter Kaufmann pôde realizar experimentos nos quais a velocidade dos elétrons era próxima à da velocidade luz (entre $0,8 \mathrm{c}$ e $0,9 \mathrm{c}$ ). [...] Tais experimentos revelaram consideráveis variaçōes na massa do elétron, as quais foram seriamente estudadas por Lorentz. Lorentz obteve a equação para a relação entre massa e velocidade e Einstein seguiu o seu caminho. (MARTINS, 2005, p.23).

É preciso notar que as experiências de Kaufmann com raios beta já não se atrelavam mais tão fortemente à busca da solução de um problema técnico, mas à investigação do comportamento das partículas atômicas. Os experimentos e as especulaçóes teóricas muitas vezes surgem de necessidades práticas, contudo, passam a ser realizados nesse distanciamento do benefício objetivado inicialmente. Para Einstein, este parece ter sido o movimento da ciência que se acentuou a partir do final do século XIX: parte do estímulo dado por um problema técnico para depois transcender complexidade teórica 
inacessível ao senso comum, mas ao qual retorna, por exemplo, embarcada em novas tecnologias.

Em sua autobiografia, ele expõe seu credo epistemológico: "[...] faz-se necessário fazer descer das regióes do olimpo platônico as noçôes fundamentais do pensamento científico e tentar descobrir sua origem terrestre." (EINSTEIN, 1980, p.29). No entanto, ele mostra também que, no sentido inverso, é pelas experiências dos sentidos que somos levados às alturas do pensamento científico e abstrato. Em uma carta a Maurice Solovine ${ }^{3}$, Einstein explica suas convicçóes epistemológicas através do esquema a seguir:

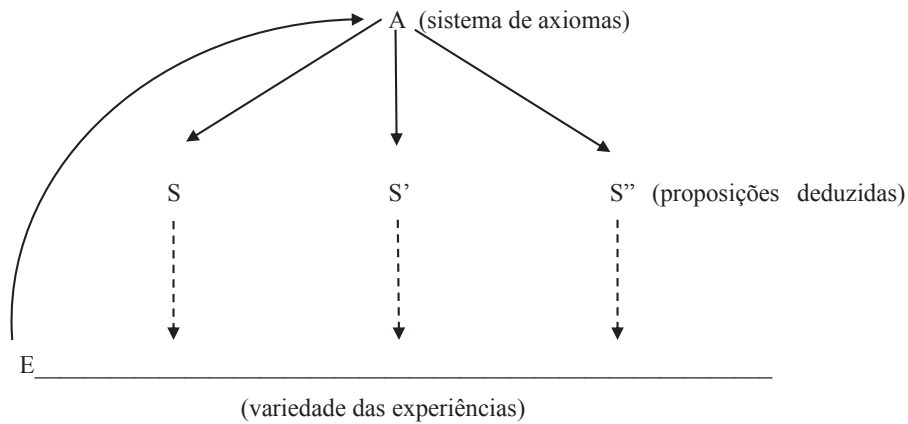

Uma linha horizontal, "E", situada abaixo no esquema, representa os dados imediatos dos nossos sentidos. No alto, o ponto "A" está representando um sistema de axiomas e, à meia altura, encontram-se, ligados a "A" por linhas descendentes, as proposiçóes deduzidas a partir do sistema. As proposiçóes $S$, $S$ ' e $S^{\prime \prime}$ ligam-se a "E" através de linhas pontilhadas descendentes. Uma linha curva completa o desenho em um gesto largo que parte de um ponto próximo à linha "E" e sobe até o ponto "A", para onde está apontada sua seta.

Simbolizando a estrutura lógico-dedutiva da teoria em relação à experiência, o esquema mostra, por sua disposição, a articulação dos diversos elementos que compóem o problema da relação entre o pensamento científico e a realidade do mundo por ele descrito. "Quando Einstein escreve em sua carta que, psicologicamente, 'A' repousa sobre ' $E$ ', devemos entender que o conhecimento parte dos dados sensíveis” (PATY, 1993, p. 412).

3́ Carta a Maurice Solovine, datada de sete de maio de 1952. (PATY, 1993, p.410). 
As linhas pontilhadas que ligam $S, S$, e $S$ ” à linha "E”, da variedade das experiências, podem evidenciar a tendência de Einstein a considerar a relação entre o pensamento científico e os dados dos sentidos de natureza diferente daquela puramente lógica que existe entre os axiomas e as proposiçôes. Como ele próprio resumiu, a passagem dos conceitos à experiência imediata dos sentidos não é como a da galinha para a canja, mas como a do número associado ao tamanho de uma roupa à própria roupa (PATY, 1993). As linhas pontilhadas mostram a dificuldade que os conceitos matemáticos da teoria enfrentam, para transpor o vão formado entre eles e as experiências dos sentidos.

A teoria da Relatividade Restrita resulta da adaptação dos conceitos da física clássica à constância da velocidade da luz nas equações de Maxwell e teve um ambiente intelectual e tecnológico favorável para a sua concepção. O problema concreto da sincronizaçáo de relógios e a necessidade de tornar o eletromagnetismo compatível com o princípio da relatividade de Galileu impeliram a nova teoria à esfera conceitual.

Num lampejo de Einstein, ocorrido durante uma visita a Michele Besso, ele percebe que a chave para todas aquelas questóes estaria na revisão dos conceitos de espaço e tempo. O ciclo que começou com os resultados negativos dos experimentos de Michelson e Morley, para determinar a velocidade da Terra em relação ao éter, e com as dificuldades de sincronização de trens e resultou na teoria da relatividade (movimento de "E" para "A") se completa no caminho descendente da teoria para os objetos técnicos (movimento de "A" para "E"), mesmo que os usuários desses objetos não percebam a atualização da teoria no aparelho. O Sistema de Posicionamento Global (GPS), por exemplo, leva em conta o efeito relativístico da menor intensidade do campo gravitacional na órbita do satélite em relação à da superfície da Terra e ainda a velocidade com que o objeto celeste trafega no espaço. "É necessário um fator de correção de algumas dezenas de microssegundos por dia para produzir dados precisos do tempo através do GPS. A correção, em geral, é feita 'automaticamente', sem que o usuário se dê conta." (YAM, 2004, p. 48).

Outro artifício que Einstein considerava capaz de fazer os conceitos descerem à experiência dos sentidos é o dos experimentos mentais. Durante o primeiro semestre de 1916, após ter chegado às equaçóes básicas da Relatividade, Einstein escreveu um livro destinado ao público de formação média e sem intimidade com o aparato matemático da física teórica. Ele acreditava que a teoria era simples, mas não estava sendo assim entendida. $\mathrm{O}$ título dado ao livro foi Über die spezialle und die allgemeine Relativitätstheorie 
(Gemeinverständlich), que podemos traduzir por $A$ teoria $d a$ relatividade especial e geral (uma exposição popular), entretanto, a tentativa de Einstein esbarrou na distância que a ciência, a partir do início do século XX, tomou do senso comum, que não pôde mais aceder à complexidade das novas teorias. "Mais tarde, Einstein diria sobre seu esforço de divulgação que o livro deveria ter sido chamado de gemeinunverständlich [incompreensível], em vez de gemeinverständlich [inteligível, ao alcance de todos]." (MOREIRA; STUDART, 2005, p. 132).

Espaço e tempo tornam-se, com Einstein, complexa abstração conceitual com a qual se estabelece uma representação teórica da realidade física. Espaço e tempo perderam o caráter de evidência que os ligava às concepçôes clássicas de Newton e Descartes e adquiriram uma formulação matemática inacessível aos sentidos e à imaginação. Ao incorporar o espaçotempo quadridimensional de Minkowski, a Relatividade descola-se de qualquer experiência sensorial, já que percebemos apenas as três dimensôes do espaço. No referido livro de popularização da teoria e também em A Geometria e a Experiência (EINSTEIN, 1921b), Einstein vale-se dos experimentos mentais para mostrar a possibilidade da existência de uma realidade que não podemos perceber, mas que podemos conceber como verdadeira, através de analogias imagináveis entre mundos de diferentes dimensões. É a essa conexão entre "A" para "E" que Einstein atribui uma natureza intuitiva (rein intuitiv), tomando a intuição aqui como um "voo mental" capaz de apreender um significado coerente da abstração matemática, próximo ao sentido assumido pela palavra, em L'Invention Mathématique de Poincaré (POINCARÉ, 1993).

O filósofo francês Henri Bergson acompanhava com bastante atenção as teorias científicas, no início do século XX, especialmente a teoria da Relatividade de Einstein e suas concepçóes de tempo e de espaço; ele percebeu o salto que a ciência esboçava em seu nível de complexidade: comentando ${ }^{4}$ a entâo recente obra de Haldene, The philosophy of humanism ${ }^{5}$, ele escreve:

Parece-me que este livro é um prolongamento importante de The reign of relativity. Os problemas são bem colocados e aprofundados: o mais importante de todos parece-me ser o da relação do concreto com o abstrato e, consequentemente, da realidade com a ciência. (BERGSON, 2002, p. 976).

${ }^{4}$ Em carta a Richard B. Haldene, datada de 30 de junho de 1922.

${ }^{5}$ HALDENE, Richard B. The philosophy of humanism and others subjects. Londres: Murray, 1922. 
A preocupação de Bergson começa na mesma direção das inquietaçóes de Einstein, mas logo adquire um caráter diferente. A leitura do livro de divulgação científica de Einstein sobre a Relatividade motivou Bergson a escrever Durée et Simultanéité. Publicado em 1922, esse polêmico livro não contesta o valor da teoria para a ciência, porém, realça a oportunidade que as novas concepçóes científicas de tempo e de espaço oferecem à Filosofia. Apesar de utilizar alguns argumentos confusos, Bergson aponta similitudes e complementaridades, como entre as múltiplas medidas do tempo para diferentes referenciais e as diferentes contraçôes da duração.

A via que Bergson elege para a apreensão da multiplicidade do tempo é, no entanto, diferente da trilhada por Einstein: o físico opta pela via inteligente, enquanto o filósofo toma a duração como intuitiva por excelência. Einstein utiliza a palavra intuição com bastante frequência, mas com um significado diferente daquele que Bergson atribui ao termo.

Em A Evolução Criadora, Bergson aponta que a vida, graças à sua capacidade inventiva, cindiu-se em vegetal, especializada em captar energia, e animal, responsável pelo espalhamento da vida graças ao poder de locomoção que a complexidade de músculos e nervos propicia. No reino animal, a inteligência desenvolveu-se nos vertebrados com o aprimoramento do sistema nervoso e do cérebro, atingindo seu grau mais elevado no ser humano, contudo, entre os invertebrados, foi o instinto o qual teve um desenvolvimento maior. Enquanto o homem planeja suas açóes inteligentemente, as abelhas, por exemplo, organizam-se guiadas por esse instinto. Apesar da cisão, instinto e inteligência conservam um caráter indiviso. Enfatiza Deleuze (1999, p. 76):

Quando a vida divide-se em planta e animal, quando o animal se divide em instinto e inteligência, cada lado da divisão, cada ramificação, traz consigo o todo sob um certo aspecto, como uma nebulosidade que acompanha cada ramo, que dá testemunho de sua natureza indivisa. Daí haver uma auréola de instinto na inteligência, uma nebulosa de inteligência no instinto, um quê de animado nas plantas, um quê de vegetativo nos animais.

$\mathrm{Na}$ humanidade da qual fazemos parte, a intuição - forma elevada do instinto - é quase inteiramente sacrificada à inteligência, todavia, ela se faz presente, vaga e descontinuamente. A intuição, dirá Bergson, é uma lâmpada quase apagada, que se reaviva apenas de vez em quando, e apenas por alguns instantes, quando um interesse vital está em jogo. 
Sobre a nossa personalidade, sobre a nossa liberdade, sobre o lugar que ocupamos no todo da natureza, sobre a nossa origem e talvez mesmo sobre o nosso destino, ela projeta uma luz vacilante e fraca, mas que não deixa de iluminar a escuridão da noite em que nos deixa a inteligência. (BERGSON, 2001, p. 240).

Bergson (2001) confere à intuição a faculdade de aceder ao conhecimento por uma via diferente da adotada pela inteligência. Simpatizar com o objeto, aceder à sua essência sem passar por suas propriedades físicas miscíveis é conhecê-lo por dentro, enquanto a atividade inteligente só permite a apreensão de um conjunto de suas características as quais, juntas, o descrevem, mas não dão a noção do todo que a intuição possibilita, quando o murmúrio interno da duração do observador coincide com a duração do objeto.

Einstein considera, por um lado, a variedade das experiências imediatas dos sentidos e, por outro, o conjunto de conceitos e proposiçóes entre os quais há uma relação de natureza lógica. A relação entre os conceitos axiomatizados, “A”, e as experiências imediatas dos sentidos, "E”, é puramente intuitiva, no sentido da penetraçáo profunda da experiência que conduz às leis elementares mais gerais (EINSTEIN, 1979, p. 121-125). Embora, num primeiro olhar, essa definiçãao de intuição pareça estar próxima da de Bergson, Michel Paty a interpreta como submetida a uma operação racional: "A intuição [...] não é apenas uma operação que se deixa descrever de maneira analítica; é uma verdadeira experiência vivida do pensamento, psicológica e subjetiva, mas apoiada em elementos intelectuais." (PATY, 1993, p. 458).

Percebemos com mais clareza o distanciamento entre as concepçóes de intuição em Einstein e Bergson, no recurso das experiências mentais adotadas pelo físico. Em A Geometria e a Experiência, ele recorre a esses experimentos que partem de um sistema de conceitos para conduzir o leitor à apreensão intuitiva da respectiva teoria:

Poderíamos representar de maneira intuitiva um universo a três dimensões, finito e, no entanto, ilimitado? [...] Antes, uma observação de natureza epistemológica: uma teoria geométrico-física é, a princípio, necessariamente desprovida do caráter intuitivo, sendo apenas um sistema de conceitos. Mas estes conceitos servem para estabelecer uma conexão lógica entre a multiplicidade de fenômenos sensíveis reais ou imaginados. Tornar uma teoria intuitiva significa, portanto, que é preciso representar esta plenitude de fenômenos no qual o grupamento esquemático é realizado pela teoria. (EINSTEIN, 1921b, p. 13). 
Através de experimentos imaginados, Einstein associa a intuição à apreensão inteligível de um sistema de conceitos que escapam aos dados imediatos dos sentidos. Trata-se, portanto, de uma intuição intelectualizada, pois ele acreditava que a Relatividade seria acessível a qualquer pessoa, graças aos experimentos mentais que propiciariam, àqueles que a eles se submetessem, a compreensão do incompreensivel. Para Einstein, esse "acesso" à teoria é o "ato intuitivo" que está a serviço da inteligência. Em termos bergsonianos, a intuição à qual Einstein se refere parece não escapar do domínio da inteligência. Para Bergson, a intuição é o ato do espírito que pressupôe a multiplicidade de contraçóes da duração; em outras palavras, a intuição nos permite captar o significado filosófico do tempo num ato que nada tem a ver com a análise inteligente e quantificadora.

Einstein, pela via inteligente, relativiza a simultaneidade de eventos, remetendo o espaço-tempo a um plano inacessível aos dados imediatos da nossa consciência, mas de cuja realidade só podemos nos convencer através de experimentos mentais, ponte entre o esquema analítico da teoria e aquilo que conseguimos imaginar.

Einstein considera essa via de acesso oferecida pelas experiências mentais intuitiva. Bergson, no entanto, concebe a intuição como método para instalarse de início na duração, dispensando os símbolos, porque "[...] a duração é o próprio estado da realidade.” (BERGSON, 2001, p. 243). Bergson faz uma espécie de curto-circuito nos caminhos entre "A" e "C": a intuição, ao invés de conectar os conceitos à experiência, dispensa a análise inteligente da teoria, oferecendo outra via para o conhecimento.

Bergson viu na teoria de Einstein a possível complementaridade entre o tempo concebido pela inteligência e o tempo captado no ato intuitivo. $\mathrm{O}$ debate entre ele e Einstein foi o início de um diálogo que se estende até os dias atuais.

Bergson assim se pronunciou:

O que eu quero estabelecer é simplesmente o seguinte: uma vez admitida a Relatividade como teoria física, nem tudo está terminado. Resta determinar o significado filosófico dos conceitos que ela introduz. Resta descobrir até que ponto ela renuncia à intuição e até que ponto ela permanece atada à intuição: resta fazer a parte do real e do convencional nos resultados aos quais ela chegou, ou, principalmente, nos intermediários que ela estabeleceu entre a posição e a solução do problema. Ao fazer este trabalho no concernente ao Tempo, perceberemos, creio, que a teoria da 
Relatividade nada tem de incompatível com o senso comum. (BERGSON, 1972, p. 1342-1345).

Ao que Einstein respondeu:

A questão se coloca então assim: o tempo do filósofo é o mesmo tempo do físico? [...] Ora, o tempo físico pode ser derivado do tempo da consciência. Primitivamente os indivíduos têm a noção da simultaneidade de percepçóes; eles podem se entender entre eles e concordarem sobre qualquer coisa que percebem; esta seria uma primeira etapa em direçáo ao tempo objetivo. Mas existem eventos objetivos independentes dos indivíduos e, da simultaneidade das percepçôes, nós passamos às dos eventos propriamente ditos. E, de fato, aquela simultaneidade não conduziu a nenhuma contradição durante longo tempo devido à grande velocidade da luz. [...] Não há, portanto, um tempo dos filósofos; apenas existe um tempo psicológico diferente do tempo dos físicos. (BERGSON, 1972, p. 1345).

Segundo Ilya Prigogine, os processos dinâmicos instáveis estão no cerne do debate entre Einstein e Bergson. O desfecho desse debate foi desastroso para Bergson, pois é unicamente admitido que ele se equivocou quanto à interpretação da Relatividade Restrita de Einstein. "Apesar de tudo, como iremos demonstrar, a existência dos processos dinâmicos instáveis reabilita até certo ponto a ideia de um tempo universal defendido por Bergson." (PRIGOGINE; STENGERS, 1984, p. 235). Prigogine (1984) afirma ainda que a polêmica nascida no encontro de Einstein com Bergson está superada, pois os tempos por eles concebidos não são completamente antagônicos. No entanto, "[...] o debate prossegue em outros níveis: o tempo é essencial, como pensava Bergson [complexo demais para a ciência]? Ou o tempo é acessório, como pensava Einstein?” (PRIGOGINE, 1991, p.21).

O universo, tomado por Prigogine como uma evolução irreversível, induz a colocação do tempo como primordial para a ciência. Todavia, o que aqui é necessário realçar é o modo como a ciência fornece o conhecimento desse universo. Bergson propóe uma ciência que não negue à intuição a validade do conhecimento fornecido por ela; em outras palavras, ele propóe uma ciência em que inteligência e intuição sejam complementares para a apreensão da realidade. A intuição, tomada no sentido de Bergson, é outra via de acesso da consciência ao mundo que a ciência inteligentemente traduz em 
símbolos. A "hipertrofia" da inteligência humana inibiu a capacidade intuitiva de apreensão do próprio estado da realidade, ou seja, da duração.

Bergson assinalou a exigência de reintegrar o conhecimento ao real, ou a inteligência na intuiçáo, exigência que define náo uma simples 'naturalização', mas uma verdadeira ontologia do conhecimento... A inteligência da matéria espacial e a intuição da duração vital são duas faces do nosso acesso ao real. (WORMS, 2001, p. 105).

Assim, Bergson não recusa nenhum direito ao conhecimento científico, frisando que esse conhecimento não nos separa da verdadeira natureza das coisas, mas apreende pelo menos uma das duas metades do ser, um dos dois lados do absoluto, um dos dois movimentos da natureza. Não há, em Bergson,

[...] a menor distinção de dois mundos, um sensível, outro inteligível, mas somente dois movimentos, ou antes, dois sentidos e o mesmo movimento: um deles é tal que o movimento tende a congelar em seu produto, no resultado que o interrompe; o outro é o que retrocede, que reencontra no produto o movimento do qual resulta. (DELEUZE, 1999, p. 127).

Nas palavras do próprio Bergson (1999a, p. 47), “[...] a metafísica exercerá, assim, por sua parte periférica, uma influência salutar sobre a ciência. Inversamente, a ciência comunicará à metafísica os hábitos de precisão que se propagarão por ela da periferia ao centro".

Bergson propóe uma filosofia verdadeiramente intuitiva, a qual realizaria uma espécie de união entre a metafísica e a ciência. Ele acreditava que a multiplicidade do tempo prevista na teoria de Einstein estava próxima do entendimento do senso comum: nos sonhos ${ }^{6}$, por exemplo, o tempo da pessoa que dorme tem contração diferente do tempo da pessoa que sonha, sendo, no entanto, ambos, sonho e sono, simultâneos.

Uma pessoa que sonha experimenta um subjetivamente longo intervalo que permanece contemporâneo com o subjetivamente muito mais curto intervalo de uma pessoa acordada, com o normal lapso do seu presente psicológico. A analogia com o paradoxo relativístico de diferentes envelhecimentos de pessoas é óbvia. Temos apenas que substituir os diferentes relógios psicológicos de duas pessoas, uma acordada e a outra

\footnotetext{
${ }^{6}$ Bergson, numa conferência feita no Institut Général Psycologique, em 26 de março de 1901, cita o relato de Alfred Maury como exemplo de um instantâneo que se desdobra em horas, e ressalta a diferença entre o tempo dos sonhos e o tempo de vigília.
} 
sonhando, pelos diferentes relógios biológicos do viajante espacial e do seu irmão que permanece na Terra. Assim, o aparente paradoxo relativístico perde muito de sua misteriosa aparência. (CAPEK, 1971, p. 249) 7 .

A multiplicidade temporal da Relatividade não é o equivalente da durée com vários graus de tensão, contudo, há uma possível complementaridade entre a primeira, fruto da inteligência, e a segunda, apreendida no ato intuitivo. No entanto, em sua confrontação com a Relatividade, na necessidade de diferenciar a análise inerente à teoria do método intuitivo, Bergson vai sustentar a existência de um só tempo, universal e impessoal, diferenciando a multiplicidade virtual da atual. Nesse ponto, o que parecia simplesmente análogo, nos pensamentos do cientista e do filósofo, torna-se complexo. A Relatividade, devido à sua intrínseca reciprocidade dos pontos de vista, não diferencia a visão real das visóes virtuais, porém, ao filósofo coube introduzir a distinção.

Em A Evolução Criadora, Bergson compara a vida a uma memória, correspondendo os gêneros ou as espécies a graus coexistentes dessa memória virtual. Segundo Deleuze (1999, p. 61), aí está

[...] uma visão ontológica que parece implicar num pluralismo generalizado. Mas, precisamente em $A$ Evolução Criadora, uma restrição importante é marcada: se dizemos que as coisas duram, é menos por si mesmas ou absolutamente do que em relação ao Todo do universo do qual elas participam, dado que suas distinçôes são artificiais.

Segundo Deleuze, em Durée et Simultanéité, Bergson recapitula todas as suas hipóteses anteriores e ainda acrescenta outra: primeiro, o pluralismo generalizado de Matéria e Memória, onde haveria uma coexistência de ritmos totalmente diferentes, duraçóes distintas e multiplicidade radical do tempo; depois, o pluralismo restrito de $A$ Evolução Criadora, ou seja, fora de nós, as coisas materiais se distinguiriam por uma certa maneira relativa de participar da nossa duraçáo; e ainda acrescenta que (hipótese considerada por ele como a mais satisfatória), sem abrir mão da multiplicidade, é suposta a existência de um só tempo, universal e impessoal, do qual tudo participaria, inclusive as nossas consciências, os viventes e todo o mundo material.

A predileção por um monismo do tempo, em Duração e Simultaneidade, explica-se pelo confronto com Relatividade. A teoria de Einstein a propósito do

${ }^{7}$ Capek refere-se ao "paradoxo dos gêmeos", proposto pelo físico francês Paul Langevin, em 1911. 
espaço e do tempo invoca conceitos tais como expansão e contração, os quais Einstein recolhia de Riemann e Bergson havia já utilizado, em Ensaio Sobre os Dados Imediatos da Consciência. Todavia, ele viu-se obrigado a distinguir a multiplicidade do tempo na Relatividade da sua própria ideia de um tempo múltiplo, afastando-se, como afirma Pearson (PEARSON, 2002), dos argumentos que encontramos em Matéria e Memória e em A Evolução Criadora.

Contração, dilatação, relatividade do movimento, todas essas noções são familiares a Bergson. Ele as emprega por sua conta. Que a duração, isto é, o tempo, seja essencialmente uma multiplicidade, é uma ideia à qual Bergson jamais renuncia. O problema, porém, é o seguinte: que tipo de multiplicidade? Bergson opunha dois tipos de multiplicidade, as multiplicidades atuais, numéricas e descontínuas, e as multiplicidades virtuais, contínuas e qualitativas. É certo que, na terminologia de Bergson, o Tempo de Einstein é da primeira categoria. O que Bergson reprova a Einstein é ter confundido os dois tipos de multiplicidade e, com isso, ter reposto a confusão do tempo com o espaço. É só aparentemente que a discussão incide sobre o seguinte: o tempo é uno ou múltiplo? O verdadeiro problema é este: qual a multiplicidade própria do tempo? (DELEUZE, 1999, p. 63).

Deleuze recupera a duração bergsoniana como um tempo único, pertencente a um conjunto que deve ser virtual, e este é o tempo único que a Relatividade de Einstein presume. Bergson concebe a duração como "[...] coexistência virtual de todos os graus em um só e mesmo tempo.” (DELEUZE, 1999, p. 68).

É, portanto, na hipótese de um tempo único que Bergson situa as multiplicidades virtuais simultâneas à nossa própria duração: "Quando estamos sentados à beira de um rio, o escoamento da água, o deslizamento de um barco e o murmúrio ininterrupto de nossa vida profunda são para nós três coisas diferentes ou uma só, como se queira." (BERGSON, 1998, p. 75).

Para Bergson, é a simultaneidade dos fluxos do movimento do barco e do voo do pássaro que se mantém na duração do nosso fluxo e e oson concebe aGUATTARI, 1980 o de Mat nos conduz à duração real, à coexistência virtual de todos os graus em um só e mesmo tempo. Einstein apenas inventou uma nova maneira de "espacializar" o tempo, porque confundiu a multiplicidade atual, simbólica e numérica, com a multiplicidade virtual, contínua e qualitativa.

As objeções que Bergson faz à teoria da Relatividade, em Durée et Simultanéité, levaram-no a defender a ideia da unidade de um tempo real, 
no qual as múltiplas contraçóes da duração coexistem. Embora aos olhos de Einstein e dos físicos da época houvesse aí um indício de que Bergson havia se perdido nas teorias científicas, a física de hoje demonstra a existência de processos dinâmicos instáveis, os quais reabilitam o tempo universal defendido por Bergson, pois permitem reconciliar a ideia fundamental de Einstein de um tempo múltiplo atado a diferentes observadores com a existência de um devir universal e criador defendida por Bergson. Assim, Bergson se concilia também com o caráter universal do tempo newtoniano. "Existem, como desejava Bergson, outros tempos além do medido por relógios, mas esses tempos passam 'juntos' para definir um devir universal." (PRIGOGINE; STENGERS, 1984, p. 343).

O tempo múltiplo da Relatividade seria, então, uma expressão matemática da reciprocidade ideal de pontos de vista sobre o universo. Conforme Bergson, a teoria de Einstein, ao invés de contradizer, confirma sua própria teoria da duração.

A pluralidade abstrata dos pontos de vista remeteria, segundo Bergson, à pluralidade concreta das consciências, de onde se deduz a pluralidade náo mais espacial, mas temporal do universo que as consciências comunicam às coisas. Da duração interna de cada consciência viva, passaríamos ao "tempo das coisas" por uma projeção a cada instante renovada. "A consciência que percebe o mundo lhe transmite, por esta própria percepção e de uma só vez, duração e simultaneidade." (SOULEZ; WORMS, 2002, p. 190).

Diante da proliferação de novos e revolucionários conceitos científicos emergentes no início do século XX, tais como a teoria da Relatividade, a qual, décadas depois, teria a bomba atômica como subproduto, Bergson reivindicava uma contrapartida intuitiva à inteligência e uma contrapartida moral à capacidade humana de controlar quantidades de energia infinitamente superiores à da escala antropométrica. Seu sonho era o de uma ciência completa, na qual os privilégios da inteligência seriam partilhados com a intuição, na qual física e metafísica se interpenetrariam metodologicamente.

Se nossos órgãos são instrumentos naturais, nossos instrumentos são por isso mesmo órgãos artificiais. [...] Porém, máquinas que [...] convertem em movimento energias potenciais acumuladas durante milhões de anos, vieram dar ao nosso organismo uma extensáo tão vasta e uma potência tão formidável, tấo desproporcional à sua dimensão e força, que certamente nada disso havia sido previsto no plano estrutural de nossa espécie: foi um acaso único, a maior conquista material do homem no planeta. [...] 
Ora, nesse corpo desmesuradamente aumentado, a alma continua o que era, demasiado pequena agora para enchê-lo, muito frágil para dirigi-lo. Daí o vácuo entre o corpo e a alma. Daí os terríveis problemas sociais, políticos, internacionais, que são outras tantas definiçóes desse vazio e que, para enchê-lo, provocam hoje tantos esforços desordenados e ineficazes: para isso seriam necessárias novas reservas de energia potencial, mas agora de natureza moral. (BERGSON, 1978, p. 256).

As teorias científicas podem partir de "E" para chegar a "A" e, em seguida, retornar a "E", mas a complexidade do mundo atual exige que a ciência avance para além do restrito espaço no qual se discute se os conceitos partem da solução de problemas práticos ou de puras especulaçôes teóricas. Faz-se necessário trazer a ciência para a mesa de debates fora do seu âmbito disciplinar, tal como o fez Bergson, no encontro de 1922 com Einstein, e a ela incorporar significados que extrapolam a lógica da ciência pela ciência.

BARRETO, Márcio. Why revisit the debate between Bergson and Einstein? Trans/form/ ação, Marília, v. 39, n. 1, p. 77-92, Jan./Mar., 2016.

\begin{abstract}
Bergson and Einstein attended the conference held in Paris at the Collège de France in April 1922. Many disagreements between the physicist and the philosopher with regard to the question of time are overcome if we consider the existence of unstable dynamic processes. However, the question of interiority of time in science still remains, and therefore also the possibility of a resumption of the complementarity between science and metaphysics - something Bergson proposed as necessary for understanding the complexity of contemporary problems. Based on the concepts of intuition in Bergson and Einstein, this article explores the difficulties of, and the potentials for, the dialogue between physics and philosophy.
\end{abstract}

KEYWORDS: Bergson. Einstein. Time.

\title{
REFERÊNCIAS
}

BERGSON, H. Mélanges. Paris: Presses Universitaires de France, 1972. . As duas fontes da moral e da religiāo. Tradução de Nathanael C. Caixeiro. Rio de Janeiro: Zahar, 1978.

. Ensaio sobre os dados imediatos da consciência. Lisboa: Ediçōes 70, 1988.

. Durée et simultanéité. Paris: Quadridge/P.U.F., 1998. 
La pensée et le mouvant. Paris: Quadridge/P.U.F., 1999a.

. Matéria e memória. São Paulo: Martins Fontes, 1999b.

. A evolução criadora. Lisboa: Ediçôes 70, 2001.

.Correspondances: textes publiés et annotés par André Robinet. Paris: Presses Universitaires de France, 2002.

. L'energie spirituelle. Paris: Presses Universitaires de France, 2003.

CAPEK, M. Bergson and modern physics. Edited by Robert S. Cohen and Marx W. Wartofsky. Dordrecht: D. Reidel, 1971.

DELEUZE, G. Bergsonismo. Rio de Janeiro: Nova Fronteira, 1999.

EINSTEIN, A. La théorie de la relativité restreinte et généralisé (mise à la portée de tout le monde). Paris: Gauthier-Villars, 1921a.

. La géométrie et l'expérience. Paris: Gauthier Villars, 1921b.

. Comment je vois le monde. Paris: Flammarion, 1979.

. Autoportrait. Paris: Inter-Éditions, 1980.

; BESSO, M. Correspondence 1903-1955. Paris: Hermann, 1972.

GALISON, P. Albert Einstein: ciência, filosofia e política. Ciência \& Ambiente, Universidade Federal de Santa Maria, n. 30, jan./jun. 2005.

HALDENE, R. The philosophy of humanism and others subjects. Londres: Murray, 1922.

LANGEVIN, P. La physique depuis vingt ans. Paris: Doin, 1923.

LÉVY-LEBLOND, J-M. L'esprit de sel. Paris: Librairie Arthème Fayard, 1981.

MARTINS, R. Física e história. Ciência e Cultura, SBPC. v. 57, n. 3, p. 25-29, jul./set. 2005.

MOREIRA, I.; STUDART, N. Einstein e a divulgação científica. Ciência \& Ambiente, Universidade Federal de Santa Maria, n. 30, p. 125-142, 2005.

PATY, M. Einstein philosophe. Paris: Presses Universitaires de France, 1993.

PEARSON, K. Ansell. Philosophy and the adventure of the virtual. London: Routledge, 2002.

POINCARÉ, H. L'invention mathématique. Paris: Éditons Jacques Gabay, 1993.

PRIGOGINE, I.; STENGERS; I. A nova aliança. Brasília: Editora da UnB, 1984. . O nascimento do tempo. Lisboa: Ediçóes 70, 1991.

SOULEZ, P.; WORMS, F. Bergson. Paris: Presses Universitaires de France, 2002. 
BARRETO, M.

WORMS, F. L'Intelligence gagnée par l' intuition? La relation entre Bergson et Kant. Les Études Philosophiques, n. 4, p. 453-464, oct./dec. 2001.

YAM, P. Einstein no dia-a-dia. Scientific American Brasil, n. 29, p. 90-95, 2004.

Recebido em 23/10/2015

Aceito em 10/12/2015 